\title{
Nonverbal priming in amnesia
}

\author{
GAIl MUSEN and LARRY R. SQUIRE \\ Veterans Affairs Medical Center and University of California, San Diego, California
}

\begin{abstract}
In this experiment, we examined whether a group of well-characterized amnesic patients would exhibit normal priming for novel nonverbal materials after a single exposure. Both amnesic patients and normal control subjects studied line figures and were then given a priming test in which they were asked to reproduce both old (studied) and new (unstudied) figures after a brief exposure. The measure of priming was the number of old patterns drawn correctly relative to the number of new patterns drawn correctly. Both subject groups reproduced more old patterns than new patterns, and the effect was similar in the two groups. In contrast, amnesic patients were significantly impaired on a recognition memory test for the items that had been presented. This study contributes to recent evidence that implicit memory can support the rapid acquisition of novel verbal and nonverbal information. Perceptual priming for such material is independent of the structures damaged in amnesia.
\end{abstract}

A central issue for the study of memory has been the nature of information that can be supported by nondeclarative (implicit) memory (for discussion of the distinction between explicit and implicit memory, and declarative and nondeclarative memory, see Hintzman, 1990; Schacter, 1987; Shimamura, 1986; Squire, 1992). One important question has been whether or not subjects can exhibit priming for entirely new information. During the 1980s, a widely held view was that priming occurred by means of the activation of already existing memory representations. Thus, it was supposed that initial exposure to an item activated a memory representation and that the same item would then be more readily perceived when it was subsequently presented (Diamond \& Rozin, 1984; Mandler, 1980; Morton, 1969, 1979; Scarborough, Cortese, \& Scarborough, 1977).

This view was challenged by studies in which implicit memory for nonwords was demonstrated by the use of a perceptual identification paradigm (Cermak, Talbot, Chandler, \& Wolbarst, 1985; Cermak, Verfaellie, Milberg, Letourneau, \& Blackford, 1991; Feustel, Shiffrin, \& Salasoo, 1983; Jacoby, 1983; Jacoby \& Dallas, 1981; Rueckl, 1990; Salasoo, Shiffrin, \& Feustel, 1985; Whitlow \& Cebollero, 1989). This finding posed a potential problem for the activation view because it suggested that priming of nonwords can occur even though nonwords do not have preexisting representations. However, the

This research was supported by the Medical Research Service of the Department of Veterans Affairs, the National Institute of Mental Health (NIMH) Grant (MH24600), the Office of Naval Research, the McKnight Foundation, and a National Institute of Mental Health (NIMH) postdoctoral fellowship to Gail Musen (MH09858). We thank Joyce Zouzounis for research assistance, Paul Clopton for developing the computer software, and Nicholas Goffeney for technical assistance. Gail Musen is now at Department of Psychology, Barnard College, Columbia University, New York, NY 10027. Correspondence concerning this article should be addressed to Larry R. Squire, Veterans Affairs Medical Center (V116a), 3350 La Jolla Village Drive, San Diego, CA 92161. interpretation of this effect was complicated for a time by reports that amnesic patients can exhibit intact priming effects for words but not for nonwords (Cermak et al., 1985; Diamond \& Rozin, 1984). It now seems likely that amnesic patients performed more poorly than normal subjects in those studies, not because they could not show priming but because normal subjects could outperform amnesic patients by engaging in declarative (explicit) memory strategies (see Haist, Musen, \& Squire, 1991; Musen \& Squire, 1991).

Because amnesic patients have damage in brain areas essential for declarative memory (Butters \& Stuss, 1989; Damasio, Graff-Radford, Eslinger, Damasio, \& Kassell, 1985; Graff-Radford, Tranel, Van Hoesen, \& Brandt, 1990; Shimamura, Jernigan, \& Squire, 1988; Squire \& Zola-Morgan, 1991), findings from amnesic patients can provide important information concerning when declarative memory strategies contribute to performance on memory tasks and when they do not. For example, Musen \& Squire (1991) demonstrated with a reading-speed paradigm that amnesic patients exhibit entirely normal acquisition of nonwords across multiple encounters when the paradigm is used. Also, similar to normal subjects, amnesic patients are more likely to judge both famous and nonfamous names as famous if the names have been encountered recently (Squire \& McKee, 1992). Nonfamous names presumably have no preexisting memory representations. Finally, amnesic patients showed normal priming for nonwords after only a single exposure using a perceptual identification paradigm (Haist et al., 1991). The findings from these studies strongly suggest that novel verbal information can be acquired implicitly and that the phenomenon occurs at full strength in amnesic patients.

The view that priming can involve the acquisition of new information, not only the activation of preexisting information, is also supported by other recent studies using novel nonverbal material. Normal subjects can learn implicitly material such as novel line patterns (Musen \& 
Treisman, 1990), three-dimensional novel objects (Schacter, Cooper, \& Delaney, 1990), and novel dot patterns (Gabrieli, Milberg, Keane, \& Corkin, 1990). In all these cases, the probability that an item exhibited priming was independent of the probability that it would be recognized. In addition, the studies with nonverbal material show that priming can sometimes be an entirely perceptual phenomenon that operates on the figural organization of visual information. Indeed, Musen (1991) reported that the same amount of priming occurred whether subjects made judgments about how the lines were connected or whether they named objects that the stimuli resembled. Also, Schacter et al. (1990) found no priming when subjects were instructed to associate 3-D objects with real objects. Thus, attaching meaning to nonverbal material is not essential for priming and can sometimes diminish it.

Testing whether amnesic patients can learn novel nonverbal material as well as normal subjects can could potentially provide confirmation of the idea that priming can be accomplished by forming new representations that do not rely on access to explicit memory. Early studies of nonverbal priming, with amnesic patients involving detecting hidden figures (Crovitz, Harvey, \& McClanahan, 1981 ) or identifying incomplete drawings (Milner, Corkin, \& Teuber, 1968; Warrington \& Weiskrantz, 1968) did not satisfactorily resolve this issue because performance was either not intact in the patients (Milner et al., 1968; Warrington \& Weiskrantz, 1968) or was tested in a group of patients but not in normal subjects (Crovitz et al., 1981).

In two recent studies of nonverbal priming, the authors performed the critical comparison between amnesic patients and normal control subjects. Gabrieli et al. (1990) studied the severely amnesic patient H.M. In the baseline condition, H.M. and the control subjects were shown combinations of five dots, each from a $3 \times 3$ dot matrix, and asked to draw figures connecting all the dots. In the study condition, subjects copied onto corresponding dot patterns a set of figures that were provided by the experimenter. Finally, they were given patterns of dots without lines and asked to draw any figure they wished that connected the dots. Subjects drew more of the items that they had previously copied than would have been expected from their performance in the baseline condition. H.M. demonstrated normal performance on this test despite his impaired recognition for the same items. Schacter, Cooper, Tharan, and Rubens (1991) also reported normal priming with a mixed population of memory-impaired patients using 3-D novel objects. They studied 6 patients. Three patients had suffered a ruptured aneurysm that caused pathology in the basal forebrain and frontal lobe. Two patients had head injuries (one had damage to the left frontal lobe confirmed by magnetic resonance imaging [MRI]). The cause of the remaining patient's amnesia was not known.

Our study followed the procedure described in Musen and Treisman (1990), using a well-characterized amnesic patient population. Each of the patients had circumscribed memory impairment as a result of bilateral diencephalic or hippocampal pathology. It is important to study such patients to confirm that perceptual priming of nonverbal material is possible for patients who have circumscribed memory impairment, identified neuropathology, and no other significant cognitive impairment. In this way, one can determine that preserved priming is independent of the diencephalon and hippocampal formation.

\section{METHOD}

\begin{abstract}
Subjects
Amnesic patients. We tested 9 amnesic patients ( 7 men and 2 women), all of whom have participated in several studies in our laboratory. Four of the patients had alcoholic Korsakoff's syndrome. They had either participated in an MRI study (Squire, Amaral, \& Press, 1990) or in a quantitative computed tomography study (Shimamura et al., 1988), which demonstrated marked reductions in the volume of the mammillary nuclei, reduced thalamic density, and frontal-lobe atrophy. Of the 5 other patients, 3 (L.M., J.L., and P.H.) had bilateral hippocampal pathology that was identified with MRI (for L.M. and J.L., Press, Amaral, \& Squire, 1989; for P.H., unpublished observations). Finally, 1 patient (M.G.) became amnesic following a bilateral medial thalamic infarction that was confirmed by MRI, and another (A.B.) became amnesic as a result of anoxia associated with cardiac arrest. All 9 patients had been
\end{abstract}

Table 1

Patient Characteristics

\begin{tabular}{|c|c|c|c|c|c|c|c|c|}
\hline \multirow[b]{2}{*}{ Patient } & \multirow[b]{2}{*}{ Age } & \multirow[b]{2}{*}{ Etiology } & \multirow[b]{2}{*}{ WAIS-R } & \multicolumn{5}{|c|}{ WMS-R } \\
\hline & & & & Attention & Verbal & Visual & General & Delay \\
\hline J.W. & 55 & Korsakoff & 98 & 104 & 65 & 70 & 57 & 57 \\
\hline V.F. & 70 & Korsakoff & 103 & 101 & 78 & 72 & 72 & 66 \\
\hline P.N. & 62 & Korsakoff & 99 & 81 & 77 & 73 & 67 & 53 \\
\hline R.C. & 73 & Korsakoff & 106 & 115 & 76 & 97 & 80 & 72 \\
\hline M.G. & 58 & Thalamic Infarcation & 111 & 113 & 89 & 84 & 86 & 63 \\
\hline J.L. & 70 & Unknown & 116 & 122 & 73 & 83 & 74 & 58 \\
\hline L.M. & 59 & Anoxia & 117 & 124 & 94 & 82 & 89 & 62 \\
\hline P.H. & 68 & Unknown & 115 & 117 & 67 & 83 & 70 & 57 \\
\hline A.B. & 54 & Anoxia & 104 & 87 & 62 & 72 & 54 & $<50$ \\
\hline Mean & 63.2 & & 107.6 & 107.1 & 75.7 & 79.5 & 72.0 & 59.7 \\
\hline
\end{tabular}

Note-WAIS-R = Wechsler Adult Intelligence Scale-Revised; WMS-R = Wechsler Memory Scale-Revised. The WAI$S-R$ and each of the five indices of the WMS-R yield a mean score of 100 in the normal population with a standard deviation of 15 . The WMS-R does not provide numerical scores for subjects who score below 50 . Therefore, the value below 50 was scored as $\mathbf{5 0}$ for computing means. 
Table 2

\begin{tabular}{lcccccc}
\hline \multicolumn{7}{c}{ Performance on Standard Memory Tests } \\
Patients & $\begin{array}{c}\text { Diagram } \\
\text { Recall }\end{array}$ & $\begin{array}{c}\text { Paired } \\
\text { Associates }\end{array}$ & $\begin{array}{c}\text { Word } \\
\text { Recall \% }\end{array}$ & $\begin{array}{c}\text { Word } \\
\text { Recognition } \%\end{array}$ & $\begin{array}{c}50 \\
\text { Words }\end{array}$ & $\begin{array}{c}50 \\
\text { Faces }\end{array}$ \\
\hline J.W. & 4 & $0-0-2$ & 29 & 90 & 29 & 34 \\
V.F. & 8 & $0-0-0$ & 27 & 91 & 27 & 31 \\
P.N. & 2 & $1-1-1$ & 29 & 83 & 31 & 31 \\
R.C. & 3 & $0-0-3$ & 19 & 85 & 37 & 30 \\
M.G. & 0 & $0-0-2$ & 52 & 81 & 30 & 34 \\
J.L. & 1 & $0-0-0$ & 40 & 93 & 31 & 20 \\
L.M. & 6 & $1-1-3$ & 47 & 97 & 30 & 37 \\
P.H. & 3 & $0-0-1$ & 27 & 84 & 36 & 34 \\
A.B. & 4 & $1-1-2$ & 33 & 83 & 32 & 33 \\
Mean & 3.4 & $0.3-0.3-1.6$ & 33 & 88 & 31 & 31.5 \\
Controls $(N=8)$ & 20.6 & $5.6-7.6-8.8$ & 71 & 97 & 41.1 & 38.1 \\
\hline
\end{tabular}

Note-The Diagram Recall score is based on delayed $(12 \mathrm{~min}$ ) reproduction of the Rey-Osterrieth figure (Osterrieth, 1944; maximum score $=36$ ). The average score for copying the figure was 26.5, a normal score (Kritchevsky, Squire, \& Zouzounis, 1988). The Paired Associate score is the number of word pairs recalled on three successive trials (maximum score $=10 /$ trial). The Word Recall score is the percentage of words recalled out of 15 across five successive study-test trials (Rey, 1964). The Word Recognition score is the percentage of words identified correctly across five successive study-test trials (yes/no recognition of 15 new words and 15 old words). The score for words and faces is based on a 24-h recognition test of 50 words or 50 faces (modified from Warrington, 1984; maximum score $=50$, chance $=25$ ). The mean scores for normal subjects shown for these tests are from Squire and Shimamura (1986). Note that N.A. is not severely impaired on nonverbal memory tests because his brain injury is primarily left unilateral.

well characterized with neuropsychological tests, which documented both the severity of the memory impairment and its selectivity (see Tables 1 and 2; also see Cave \& Squire, 1991; Musen \& Squire, 1991). The present study was concerned with overall performance of amnesic patients, and the patients are therefore presented here as a single group.

The 9 amnesic patients averaged 63 years of age (range $=53-73$ ) and 13.8 years of education (range $=9-19$ ). They had an average Wechsler Adult Intelligence Scale-Revised (WAIS-R) of 107.6. Individual IQ and Wechsler Memory Scale-Revised (WMS-R) index scores appear in Table 1 . Immediate and delayed (12 min) recall of a short prose passage averaged 5.2 and 0 segments, respectively (21 segments total; Gilbert, Levee, \& Catalano, 1968). Scores on other memory tests appear in Table 2 . Note that the scores on the word recall test in Table 2 are above zero because on this test of immediate recall, several items can be retrieved from immediate memory, which is intact in amnesia. In addition, the mean score on the Dementia Rating Scale (Mattis, 1976) was 133.8 (maximum $=144$, range $=125-143$ ), with most of the points lost on the memory subportion of the test ( 5.8 points). The average score on the Boston Naming Test was 55.0 (range $=\mathbf{4 8 - 5 8}$ ). Scores for normal subjects on these same tests can be found elsewhere (Janowsky, Shimamura, Kritchevsky, \& Squire, 1989; Squire et al., 1990).

Healthy control subjects. The control group for the amnesic patients consisted of 8 men and 4 women. They were either employees or volunteers at the San Diego Affairs Medical Center or were retired employees from the University of California, San Diego. They averaged 61.3 years of age (range $=53-74$ ) and 14.1 years of education (range $=12-17$ ) and obtained WAIS-R subtest scores of 21.8 for information (compared with 20.3 for amnesic patients) and $\mathbf{5 5 . 5}$ for vocabulary (compared with $\mathbf{5 5 . 5}$ for the amnesic patients). Immediate and delayed recall of the short prose passage was 7.1 and 6.1 segments, respectively.

\section{Stimuli}

Figure 1 shows examples of the stimuli. Two hundred thirty patterns were generated, 30 of which were used to assess the threshold for the priming test and were not reused in the main experiment.
The patterns were generated from a $3 \times 3$ dot matrix. They consisted of five connected lines joining dots in the matrix. The patterns were generated in a pseudorandom fashion. First, a random-number generator was used to designate the points to connect. A computer program then checked and eliminated pattern repetitions. We eliminated by eye as many simple translations and rotations as possible. In the experiment, we used a mask consisting of all possible lines that could be drawn in a $3 \times 3$ matrix

The patterns were presented in white on black using an IBM laptop computer in conjunction with a CGA graphics monitor. The monitor screen measured $26.7 \times 20.3 \mathrm{~cm}$. Each subject was seated approximately $57 \mathrm{~cm}$ from the screen so that each pattern subtended approximately $2.4^{\circ}$ of visual angle. The displays of the four patterns used in the recognition tests were arranged on the screen in the four quadrants of an imaginary square subtending about $7.6^{\circ} \times 7.6^{\circ}$ of visual angle.

\section{Procedure}

There were seven phases in each experimental session. Each phase and the number of trials per phase are listed in Table 3, described below.

Phase 1: Threshold determination. To obtain an exposure duration for each subject, 30 patterns not presented in the main experiment were used to determine the exposure duration at which each subject could reproduce correctly about $50 \%$ of the patterns. If the subjects needed more than $\mathbf{3 0}$ trials to establish the exposure duration, the 30 patterns were repeated until the criterion was determined. Each pattern was presented briefly (see below), followed immediately by a mask consisting of all possible lines that could be drawn in the $3 \times 3$ matrix of dots. The subjects then were asked immediately to draw the pattern they had seen by connecting the appropriate dots in the $3 \times 3$ matrices provided on sheets of paper. A pattern was considered correct only if all of its component lines were produced correctly. The first pattern was presented for a duration of $1 \mathrm{sec}$. If the subject correctly reproduced three consecutive items, the exposure time was decreased by $100 \mathrm{msec}$. Similarly, if three consecutive items were reproduced incorrectly, the exposure duration was increased by $100 \mathrm{msec}$. After approximately 20 trials, exposure durations were altered in $17-\mathrm{msec}$ increments until 
Table 3

Experimental Procedure

\begin{tabular}{cl}
\hline Phase & \multicolumn{1}{c}{ Description } \\
\hline 1 & Threshold determination \\
2 & Study 20 items \\
3 & Priming test (20 old items, 20 new items) \\
4 & Four-alternative forced-choice recognition memory test (20 trials) \\
5 & Study 20 different items \\
6 & Priming test $(20$ old items, 20 new items) \\
7 & Four-alternative forced-choice recognition memory test (20 trials) \\
\hline
\end{tabular}

a subject could reproduce correctly about half of a sequence of eight items. When a threshold duration was selected, 4 more trials were given to ensure that the subject's performance was stable at about $50 \%$ correct. The average number of trials needed to determine a threshold value was 29.4 (range $=28-40$ ).

In Test Session 2 (5-6 months later), the threshold exposure duration was initially set at $100 \mathrm{msec}$ more than the value that had been used during Session 1 . After 4 trials at this exposure duration, the duration was changed to the value used during Session 1. During the next 8 trials, if three, four, or five items were reproduced correctly, the subjects were given 4 additional trials to confirm that this threshold value was suitable. If fewer than three or more than five items were reproduced correctly, the threshold was increased or decreased by $17 \mathrm{msec}$, and 8 more trials were given. The average number of trials needed to obtain the threshold was 18.2 (range $=16-24$ ). In Session 3, in which only amnesic patients participated, the same procedure was used. This time an average of 18.7 trials (range $=16-24$ ) were needed to select the exposure duration for each subject.

Phase 2: Study. The subjects were given 20 patterns to study. These patterns were not used for threshold determination. On each study trial, a fixation point appeared in the center of the screen for
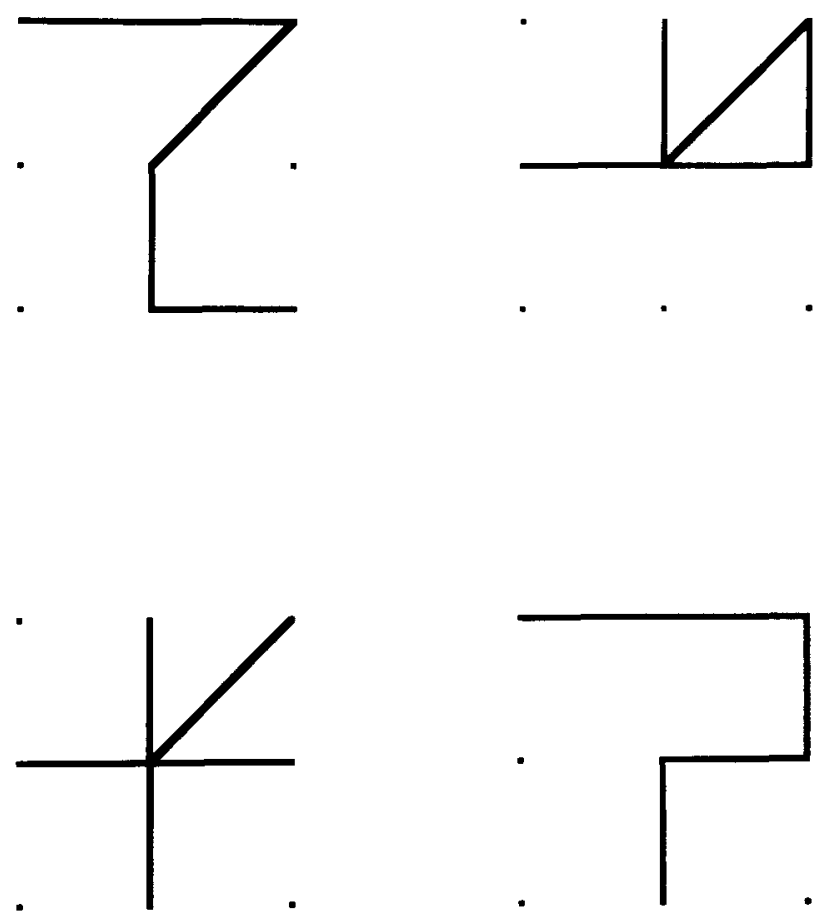

Figure 1. Examples of stimuli used in the experiment.
$250 \mathrm{msec}$, followed by a pattern that appeared for $10 \mathrm{sec}$. The subjects were instructed to try to remember the patterns so that they would be able to choose the one they had seen from among similar distractors.

Phase 3: Priming test. Immediately after the study phase, each studied ("old") pattern was presented alone, followed by a mask after the predetermined exposure duration. Equal numbers of new patterns were randomly intermixed with the old ones, with the constraint that no more than three old or new patterns were presented successively. The subjects drew what they had seen onto a sheet of paper consisting of a predrawn $3 \times 3$ matrix of dots. The subjects were encouraged to guess, if necessary, and they produced at least part of the pattern on every trial. The subjects were not informed that any of the patterns had been previously studied. If they inquired about the purpose of this phase of the test, they were told that it was a filler task to control the length of delay between the study phase and the recognition test. The drawing was selfpaced - when the subject had finished drawing a pattern, the experimenter pressed a key to begin the next trial. Priming was measured by comparing the numbers of old and new patterns reproduced correctly.

Phase 4: Recognition test. A four-alternative forced-choice test was given immediately after the priming test. On each trial, one studied pattern was presented together with three new patterns randomly placed in the four corners of the screen. Thus, the old items on the priming test were the same as the correct items in the recognition test. For each trial, the three distractors were rather similar to the correct pattern, differing in at most three lines from the target item. The subjects were asked to point to which stimulus they had previously studied. The patterns remained on the screen until the subjects responded; the experimenter then pressed a key to begin the next trial.

Phases 5-7. These three phases repeated Phases 2-4 (see Table 3).

Number of experimental sessions for each subject group. The control subjects participated in two experimental sessions and the amnesic patients participated in three sessions. Sessions 1 and 2 were separated by 5.2 months (range $=5-6$ months), and Session 3 (in which only amnesic patients participated) occurred an average of 5.3 months after Session 2. Amnesic patients were tested three times and control subjects two times to reduce variability in each subject's test scores. Because fewer amnesic patients than control subjects were available, we tested amnesic patients on one more occasion than we did control subjects. In each session, the same pool of 200 items was used, but different items were selected as study items and distractor items for the recognition memory test (as described below).

Assignment of test materials across the three experimental sessions. In the first session, there were two study sets of $\mathbf{4 0}$ patterns each. Half the subjects in each group studied one set, and half the subjects studied the other set. For each subject group, the patterns not studied were used as new items in the priming test. The remaining 120 patterns were used as distractor items on the recognition memory test. In Session 2, two new sets of $\mathbf{4 0}$ study items were selected from the 120 distractor items that had appeared on the two recognition tests in Session 1. The remaining 40 items from 


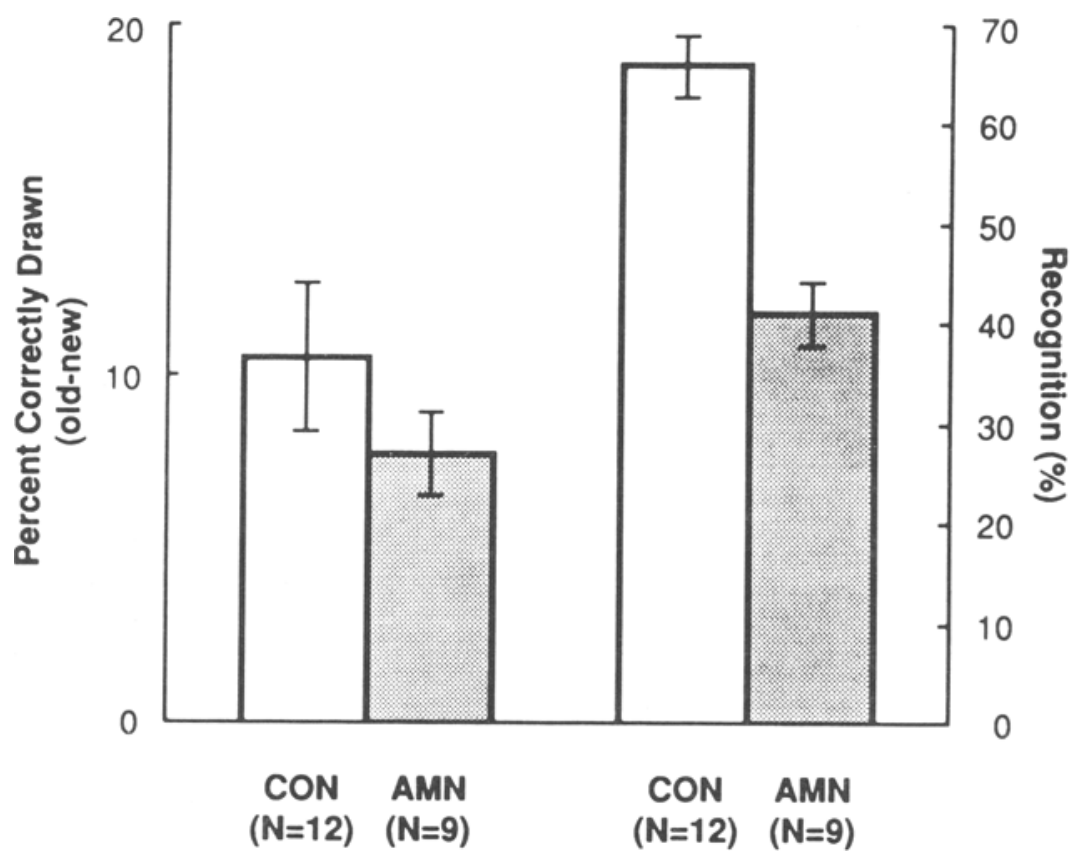

Figure 2. The left two bars show equivalent priming for amnesic patients (AMN) and control subjects (CON). Priming was measured by subtracting the percent of correctly drawn new patterns from the percent of correctly drawn old items. The right two bars show scores on a four-alternative forced-choice recognition memory test.

the distractor set in the original tests, along with the 80 items from both study sets, were now used as distractor items in the recognition test. The remaining $\mathbf{4 0}$ distractors from Session 1 were reused as distractors in Session 2 . In Session 3 (in which only the amnesic patients participated), all available 200 test items were repooled. Eighty items were assigned to two study lists of $\mathbf{4 0}$ items each (as before, the patterns not studied were used as new items on the priming test), and the remaining 120 items were used for distractor items on the recognition test. As in the previous two sessions, patterns used for half the subjects were used as new items on the priming test for the other half of the subjects, and vice versa. Musen and Treisman (1990) and Musen (1991) found that reusing the same stimuli in this paradigm did not complicate the results. Specifically, this ensured that accrued familiarity was the same for both tests.

\section{RESULTS}

\section{Priming Test}

Priming was measured as the average score from the two test sessions for the control subjects and the three sessions for the amnesic patients. Across the two test sessions, the normal subjects reproduced $68.6 \%$ of the old patterns correctly, compared with $58.2 \%$ of the new patterns. Across the three sessions, the amnesic patients reproduced $60.1 \%$ of the old patterns correctly and $52.5 \%$ of the new patterns. Thus, normal subjects had a $10.4 \%$ facilitation score (old minus new), and amnesic patients had a $7.6 \%$ facilitation score (Figure 2). A two-way analysis of variance (ANOVA) revealed no group effect $(F=$ 2.1 ), a significant effect of old versus new $[F(1,19)=$ $\left.44.5, M S_{\mathrm{e}}=3.0, p<.001\right]$, and no interaction $(F=1.1)$.
Averaged across test sessions, facilitation scores ranged from $0 \%-23 \%$ for control subjects and from $1 \%-13.2 \%$ for amnesic patients. Musen and Treisman (1990) and Musen (1991) found that normal college students had facilitation scores ranging from $7 \%-16 \%$ after a single exposure to these same patterns, depending on encoding instructions and the delay interval. Although there was a numerical difference in the facilitation scores obtained by the two subject groups in the present study, further examination of the data indicated that this difference resulted entirely from the scores of 2 of the 12 control subjects. These 2 control subjects scored considerably higher, on both test occasions, than any of the other control subjects (23.8\% facilitation score for the 2 subjects, compared with $13.8 \%$ for the subject with the next highest facilitation score). When the 2 subjects were excluded, the facilitation score for the control subjects was reduced from $10.4 \%$ to $7.8 \%$ (compared with $7.6 \%$ for the amnesic patients). Accordingly, it seems unlikely that the numerical difference observed between the two groups is meaningful. The high facilitation scores for the 2 subjects were probably not caused by their use of a verbal labeling strategy. Musen (1991) found that when normal subjects were explicitly instructed to verbally label these same figures, the priming effect did not differ from when the subjects were asked to count how many horizontal, diagonal and vertical lines were in each figure.

Because of the visuospatial problems known to be associated with Korsakoff's syndrome (Talland, 1965), we analyzed separately the data for the 4 patients with this 
diagnosis. The patients with Korsakoff's syndrome exhibited slightly more priming than did the other amnesic patients (Korsakoff patients, $8.1 \%$ facilitation; other amnesic patients, $7.2 \%$; control subjects, $10.4 \%$; all $p s>.10$ ).

To determine whether there was a priming effect for each individual test session, we performed separate ANOVAs for priming performance for the two test sessions in which both groups participated. The pattern of results was the same for both test sessions-namely, there was no group effect $(p s>.10)$, there was an effect of old versus new ( $p s<.005$ ), and there was no interaction. The mean facilitation scores for each test session were as follows: control subjects in Test Session $1,12.1 \%$, amnesic patients, $9.2 \%$; control subjects in Test Session 2, $8.8 \%$, amnesic patients, $5.3 \%$; and amnesic patients in Test Session 3, 8.0\%. There was no effect of test order on the magnitude of priming. Nevertheless, as the means reported above indicate, there was somewhat less priming in Test Session 2 for both groups of subjects than there was in Test Session 1. There were no group $x$ test session or group $\times$ old $/$ new interactions.

We also performed an item analysis to determine whether items differed in difficulty and, more importantly, whether there was an interaction between group and item difficulty. For the two test sessions in which both groups participated, we found that there was an effect of item difficulty $(p s<.05)$, because certain items were more difficult than others. However, that there was no group $x$ item difficulty interaction $(F \mathrm{~s}<5.5)$ indicates that both groups were making errors on the same patterns. This finding strengthens the conclusion that the two groups were performing similarly.

Finally, we determined that the two subject groups were similar with respect to the number of new patterns drawn correctly $\mathbf{5 8 . 2 \%}$ for control subjects vs. $52.5 \%$ for amnesic patients, $p>.20$ ), indicating that there was no difference in baseline perceptual abilities. This $5.7 \%$ baseline difference does not pose a problem in interpreting the results because there was also a comparable (and nonsignificant) difference in the ability to draw old items correctly $(68.6 \%$ vs. $60.2 \%$ for normal subjects and amnesic patients, respectively). Thus, although the normal subjects had slightly better baseline perceptual abilities, both groups improved their performance comparably on old items relative to new items. The average exposure duration used to present the patterns during study was also similar for the two groups [amnesic patients, $2.06 \mathrm{sec}$; control subjects, $1.66 \mathrm{sec} ; t(19)=1.4, p>.15$ ]

\section{Recognition Test}

Recognition performance was based on the average scores from the three test sessions for the amnesic patients and the two test sessions for the control subjects. On the four-alternative forced-choice recognition test, the amnesic patients performed significantly more poorly than the normal control subjects $\left[F(1,19)=34.5, M S_{\mathrm{e}}=\right.$ $94.0, p<.001]$. Amnesic patients scored $40.9 \%$ correct, and normal control subjects scored $66.0 \%$ correct (chance is $25 \%$; Figure 2). We also performed a separate ANOVA that included test session as a factor ( 2 test sessions $\times$ 2 groups). This analysis revealed a group difference $\left[F(1,19)=47.6, M S_{\mathrm{e}}=176.4, p<.005\right]$, no effect of test order, and an interaction of group $\times$ test session $\left[F(1,19)=4.89, M S_{\mathrm{e}}=59.4, p<.05\right]$. The interaction was due to the fact that amnesic patients performed somewhat worse on the second recognition test $(41 \%$ vs. $34.4 \%$ ), whereas the normal subjects performed somewhat better $(64.4 \%$ vs. $68.3 \%)$. On the third test session, amnesic patients scored $44.7 \%$ correct. The finding that amnesic patients performed well above chance on this test of recognition memory is consistent with previous findings that recognition tests are sensitive methods for detecting residual memory in otherwise severely amnesic patients, especially when the retention interval is short (Cohen \& Squire, 1980; Hirst, Johnson, Phelps, \& Volpe, 1988; Mayes, Meudell, \& Neary, 1980; Musen, Shimamura, \& Squire, 1990).

\section{GENERAL DISCUSSION}

This experiment demonstrated that priming of novel nonverbal material occurs after a single study exposure in amnesic patients. In contrast, explicit memory for the stimuli, as measured by a forced-choice recognition memory test, was significantly better for control subjects than for amnesic patients. The amount of priming did not differ between the control subjects and the amnesic patients, although a small numerical difference (2.8\%) was evident. This difference apparently was due to unusually high facilitation scores for 2 of the 12 control subjects. These results confirm other recent findings with nonverbal stimuli in which different test materials, different test paradigms, and different patient populations were used (Gabrieli et al., 1990; Schacter et al., 1991). Thus, novel nonverbal material can be acquired implicitly-in other words, independently of explicit memory.

It is clear that priming can involve the creation of new memory representations (as in the present experiment) and does not reflect simply the activation of preexisting memory representations. Thus, implicit memory can support the rapid acquisition of new information regardless of whether the new information is verbal (e.g., a nonword; Haist et al., 1991; Musen \& Squire, 1991) or nonverbal (e.g., a line figure).

Recent studies using positron emission tomography (PET) have provided some information about the neural basis of priming (Squire, Ojemann, Miezin, Petersen, Videen, \& Raichle, 1992). Word-completion priming of visually presented words depended on changes in right extrastriate cortex. In agreement with the PET findings, a divided visual-field study of normal subjects (Marsolek, Kosslyn, \& Squire, 1992) found that the right hemisphere was more important than the left for form-specific word priming. It had previously been suggested that a left posterior word-form area is the locus of priming for words and pronounceable nonwords (Petersen, Fox, Snyder, \& 
Raichle, 1990; Schacter, 1990; Tulving \& Schacter, 1990). This proposal is not inconsistent with the finding that the right hemisphere is especially important for formspecific priming, because it is possible that perceptual priming is supported by multiple cortical areas. The left posterior cortex might be sensitive to orthographic regularities among words, whereas the right hemisphere is specialized to detect physical features such as typecase, font, and size. It is not known from PET studies what areas are activated during the processing of novel nonverbal material. However, because the stimuli in the present study are processed largely by their perceptual properties (i.e., their form), the locus of the priming effect for these stimuli may also be in the right posterior hemisphere.

With respect to pictorial stimuli, inferotemporal cortex is important for processing and representing visual objects (Mishkin, 1982; Sergent, Ohta, \& MacDonald, 1992; see Plaut \& Farah, 1990, for a review). Schacter et al. (1991) and Cooper, Schacter, Ballesteros, and Moore (1992) have suggested that inferotemporal cortex may be an important locus for the priming of pictorial stimuli. Although inferotemporal cortex may be important, it seems likely that perceptual priming of nonverbal information could be supported by any number of brain areas in the occipital, parietal, and temporal lobes that have been implicated for visual information processing (Felleman \& Van Essen, in press; Kaas, 1989; Ungerleider \& Desimone, 1986; Zeki \& Shipp, 1988).

Recently, studies have investigated the question of what properties are preserved within a memory representation that supports implicit memory for nonverbal material. Cave and Squire (1992) reported that priming for visually presented objects was reduced when the shading of an object was changed from study to test or when a different example of a study object was presented at test (i.e., a different kind of airplane). In another study involving 3D novel objects, priming effects did not diminish when size or left/right orientation was changed from study to test (Cooper et al., 1992). Thus, it is likely that the representation that supports priming contains information about the relationships between component parts of the stimuli and that priming will occur unless these relationships are disrupted. Further research is needed to determine precisely what information is stored within representations of nonverbal stimuli.

In summary, the present findings agree with recent studies that have investigated priming for novel verbal material after either multiple (Musen \& Squire, 1991) or single (Haist et al., 1991) study trials and priming of novel nonverbal material after a single study trial (Gabrieli et al., 1990; Schacter et al., 1991). The present study provides additional evidence that novel nonverbal material can be acquired implicitly in a single study trial and that this learning occurs independently of brain areas required for declarative (explicit) memory. Based on information from previous studies, which indicated that priming of such nonverbal material is independent of semantic pro- cessing (Musen, 1991; Schacter et al., 1990), it seems likely that the priming effect for these patterns is a purely perceptual phenomenon.

\section{REFERENCES}

Butrers, N., Stuss, D. T. (1989). Diencephalic amnesia. In F. Boller \& J. Grafman. Handbook of neuropsychology (pp. 107-148). Amsterdam: Elsevier.

Cave, C. B., SQuire, L. R. (1991). Equivalent impairment of spatial and nonspatial memory following damage to the human hippocampus. Hippocampus, 1, 329-340.

CAve, C. B., \& SQuire, L. R. (1992). Intact and long-lasting repetition priming in amnesia. Journal of Experimental Psychology: Leaming, Memory, \& Cognition, 18, 509-520.

Cermak, L. S., Talbot, N., Chandler, K., Wolbarst, L. R. (1985). The perceptual priming phenomenon in amnesia. Neuropsychologia, 23, 615-622.

Cermak, L. S., Verfaelue, M., Milberg, W., Letourneau, L., - BLACKFord, S. (1991). A factor analysis of perceptual identification priming in alcoholic Korsakoff patients. Neuropsychologia, 29. 725-736.

Cohen, N. J., Squire, L. R. (1980). Preserved learning and retention of pattern analyzing skill in amnesia: Dissociation of knowing how and knowing that. Science, 210, 207-209.

Cooper, L. A., Schacter, D. L., Ballesteros, S., a Moore, C. (1992). Priming and recognition of transformed three-dimensional objects: Effects of size and reflection. Joumal of Experimental Psychology: Learning, Memory, \& Cognition, 18, 43-57.

Crovitz, H. F., Harvey, M. T., a McClanahan, S. (1981). Hidden memory: A rapid method for the study of amnesia using perceptual learning. Cortex, 17, 273-278.

Damasio, A. R., Graff-Radford, N. R., Eslinger, P. J., Damasio, H., \& Kassell, N. (1985). Amnesia following basal forebrain lesions. Archives of Neurology, 42, 263-271.

Dinmond, R., Rozin, P. (1984). Activation of existing memories in anterograde amnesia. Joumal of Abnormal Psychology, 93, 98-105.

Felleman, D., Van Essen, D. (1991). Distributed hierarchical processing in primate cerebral cortex. Cerebral Conex, 1, 1-47.

Feustel, T. C., Shiffrin, R. M., Salasoo, A. (1983). Episodic and lexical contributions to the repetition effect in word identification. Journal of Experimental Psychology: General, 112, 309-346.

Gabrieli, J. D. E., Milberg, W., Keane, M. M., Corkin, S. (1990). Intact priming of patterns despite impaired memory. Neuropsychologia, 28, 417-427.

Gilbert, J., Levee, R., \& Catalano, K. (1968). A preliminary report on a new memory scale. Perceptual \& Motor Skills, 27, 277-278.

Graff-Radford, N. R., Tranel, D., Van Hoesen, G. W., a Brandt, J. (1990). Diencephalic amnesia. Brain, 113, 1-25.

HAIST, F., MUSEN, G., \& SQUIRE, L. R. (1991). Intact priming of words and nonwords in amnesia. Psychobiology, 19, 275-285.

Hintzman, D. (1990). Human leaming and memory: Connections and dissociations. Annual Review of Psychology, 41, 109-139.

Hirst, W., Johnson, M. K., Phelps, E. A., Volpe, B. T. (1988). More on recognition and recall in amnesiacs. Journal of Experimental Psychology: Learning. Memory \& Cognition, 14, 758-762.

JACOBY, L. L. (1983). Remembering the data: Analyzing interactive processes in reading. Joumal of Verbal Leaming \& Verbal Behavior, 22, 485-508

JACOBY, L. L., \& DALLAS, M. (1981). On the relationship between autobiographical memory and perceptual learning. Joumal of Experimental Psychology: General, 3, 306-340.

Janowsky, J. S., Shimamura, A. P., Krutchevsky, M., Souire, L. R. (1989). Cognitive impairment following frontal lobe damage and its relevance to human amnesia. Behavioral Neuroscience, 103, 548-560.

KAAS, J. (1989). Why does the brain have so many visual areas? Journal of Cognitive Neuroscience, 1, 121-135.

Kritchevsky, M., SQuire, L. R., \& Zouzounis, J. A. (1988). Tran- 
sient global amnesia: Characterization of anterograde and retrograde amnesia. Neurology, 38, 213-219.

Mandler, G. (1980). Recognizing: The judgment of previous occurrence. Psychological Review, 87, 252-271.

Marsolek, C. J., Kosslyn, S. M., \& Squire, L. R. (1992). Formspecific visual priming in the right cerebral hemisphere. Journal of Experimental Psychology: Leaming, Memory, \& Cognition, 18, 492-508.

Matris, S. (1976). Dementia rating scale. In R. Bellack \& B. Keraso (Eds.), Geriatric psychiatny (pp. 77-121). New York: Grune \& Stratton.

Mayes, A., Meudell, P., \& Neary, D. (1980). Do amnesics adopt inefficient encoding strategies with faces and random shapes? Neuropsychologia, 18, 527-540.

Milner, B., Corkin, S., \& Teuber, H. L. (1968). Further analysis of the hippocampal amnesic syndrome 14 year follow-up study of H.M. Neuropsychologia. 6, 215-234.

Mishkin, M. (1982). A memory system in the monkey. Proceedings of the Royal Society of London, 298, 85-95.

Morton, J. (1969). Interaction of information in word recognition. Psychological Review, 76, 165-178.

MorToN, J. (1979). Facilitation in word recognition: Experiments causing change in the logogen models. In P. A. Kolers, M. E. Wrolstad, \& H. Bouma (Eds.), Processing of visible language (pp. 259-268). New York: Plenum.

MUSEN, G. (1991). Effects of verbal labelling and exposure duration on implicit memory for visual patterns. Joumal of Experimental Psychology: Leaming, Memory, \& Cognition, 17, 954-962.

Musen, G., Shimamura, A. P., Squire, L. R. (1990). Intact textspecific reading skill in amnesia. Joumal of Experimental Psychology: Leaming, Memory, \& Cognition, 16, $1068-1076$.

MUSEN, G., SQUIRE, L. R. (1991). Normal acquisition of novel verbal information in amnesia. Joumal of Experimental Psychology: Learning, Memory, \& Cognition, 17, 1095-1104.

Musen, G., * Treisman, A. (1990). Implicit and explicit memory for visual patterns. Joumal of Experimental Psychology: Leaming, Memory, \& Cognition, 16, 127-137.

OSterRieth, P. A , (1944). Le test de copie d'une figure complexe [The test of copying a complex figure]. Archives de Psychologie, 30 , 206-356.

Petersen, S. E., Fox, P. T., SNyder, A. Z., \&ukchle, M. E. (1990). Activation of extrastriate and frontal cortical areas by visual words and word-like stimuli. Science, 249, 1041-1044.

Plaut, D. C , Farah, M. J. (1990). Visual object representation: Interpreting neurophysiological data within a computational framework. Journal of Cognitive Neuroscience, 2, 320-343.

Press, G., Amaral, D. G., SQuire, L. R. (1989). Hippocampal abnormalities in amnesic patients revealed by high-resolution magnetic resonance imaging. Nature, 341, 54-57.

REY, A. (1964). L'examen clinique psychologie. Paris: Presses Universitaires de France.

RUECKL, J. G. (1990). Similarity effect in word and pseudoword repetition priming. Joumal of Experimental Psychology: Leaming, Memory, \& Cognition, 16, 374-391.

Salasoo, A., Shiffrin, R. M., Feustel, T. C. (1985). Building permanent codes: Codification and repetition effects in word identification. Joumal of Experimental Psychology: General, 114, 50-77.

Scarborough, D. L., Cortese, C., Scarborough, H. S. (1977). Frequency and repetition effects in lexical memory. Joumal of Experimental Psychology: Human Perception \& Peformance, 3, 1-17.

SCHACTER, D. L. (1987). Implicit memory: History and current status.
Journal of Experimental Psychology: Learning, Memony, \& Cognition, 13, $501-518$.

Schacter, D. L. (1990). Perceptual representation systems and implicit memory: Toward a resolution of the multiple memory systems debate. In A. Diamond (Ed.), Development and neural bases of higher cognitive function (pp. 543-571). New York: Annals of the New York Academy of Science.

Schacter, D. L., Cooper, L. A., Delaney, S. M. (1990). Implicit memory for unfamiliar objects depends on access to structural descriptions. Joumal of Experimental Psychology: General, 119, 5-24.

Schacter, D. L., Cooper, L. A., Tharan, M., Rubens, A. B (1991). Preserved priming of novel objects in patients with memory disorders. Joumal of Cognitive Neuroscience, 3, 118-131.

Sergent, J, , Oht A, S., \& MacDonald, B. (1992). Functional neuroanatomy of face and object processing. A positron emission tomography study. Brain, 15, 15-36.

Shimamura, A. P. (1986). Priming effects in amnesia: Evidence for a dissociable memory function. Quarterly Joumal of Experimental Psychology, 38A, 619-644.

Shimamura, A. P., Jernigan, T. L., SQuire, L. R. (1988). Korsakoff's syndrome: Radiological (CT) findings and neuropsychological correlates. Journal of Neuroscience, 8, 4400-4410.

SQUTRE, L. R. (1992). Memory and the hippocampus: Synthesis of findings with rats, monkeys, and humans. Psychological Review, 99, 195-231.

Squire, L. R., Amaral, D. G., Press, G. A. (1990). Magnetic resonance measurements of hippocampal formation and mammillary nuclei distinguish medial temporal lobe and diencephalic amnesia. Journal of Neuroscience, 10, 3106-3117.

SQUire, L. R., MCKEE, R. (1992). The influence of prior events on cognitive judgments in amnesia. Joumal of Experimental Psychology: Learning, Memory, \& Cognition, 18, 106-115.

Squire, L. R., Ojemann, J. G., Miezin, F. M., Petersen, S. E., VIDEEN, T. O., RAKCHLE, M. E. (1992). Activation of hippocampus in normal humans: A functional anatomical sudy of memory. Proceedings of the National Academy of Sciences, USA, 89, 1837-1841.

SQuire, L. R., Shimamura, A. P. (1986). Characterizing amnesic patients for neurobehavioral study. Behavioral Neuroscience, 100 , 866-877.

SQutre, L. R., Zola-Morgan, M. (1991). The medial temporal lobe memory system. Science, 253, 1380-1386.

TAlLAND, G. A. (1965). Deranged memory. New York: Academic Press.

Tulving, E., Schacter, D. L. (1990). Priming and human memory systems. Science, $247,301-306$.

Ungerleider, L., \& Desimone, R. (1986). Cortical connections of visual area MT in the Macaque. Journal of Comparative Neurology, 248, 190-222.

WARRINGTON, E. K. (1984). Recognition memory test. Windsor, U.K.: FER-Nelson.

WarRIngton, E. K., Weiskrantz, L. (1968). A new method of testing long-term retention with special reference to amnesic patients. Nature, 217, 972-974.

Whitlow, J. W., JR., \& Cebollero, A. (1989). The nature of word frequency effects on perceptual identification. Joumal of Experimental Psychology: Learning, Memory, \& Cognition, 15, 643-656.

ZEKI, S., * SHIPP, S. (1988). The functional logic of cortical connections. Nature, 325, 311-317.

(Manuscript received August 12, 1991; revision accepted for publication January 10, 1992.) 